\title{
Air pollution exposure and COPD among miners, ex- miners and non-miners in Northern Tanzania: A cross-sectional study
}

Ngweina Francis Magitta ( $\square$ ngweina.magitta@gmail.com )

University of Dar es Salaam

Meshack Denson Shimwela

Amana Regional Referral Hospital

Anna Alphonce Sanga

Muhimbili National Hospital

Sapna Jitendra Madas

Chest Research Foundation

Julius David Mwaiselage

Ocean Road Cancer Institute

Anil Kumar Namdeo

Newcastle College

Komalkirti Keshavkiran Apte

Chest Research Foundation

Sandeep Santoshi Salvi

Chest Research Foundation

Ricahrd William Walker

Newcastle Upon Tyne Hospitals NHS Foundation Trust

Research article

Keywords: chronic obstructive pulmonary disease, risk factors, mining, air pollution, cigarette smoking, spirometry.

Posted Date: September 19th, 2019

DOI: https://doi.org/10.21203/rs.2.14644/v1

License: (c) (1) This work is licensed under a Creative Commons Attribution 4.0 International License.

Read Full License 


\section{Abstract}

Background: There is a substantial burden due to Chronic Obstructive Pulmonary Disease (COPD) contributes to a substantial burden of diseases in developed countries. The existing unregulated mining activities in Africa, often without proper protective gear, could expose miners to excessive air pollution levels and subsequent development of COPD.

Methods: We conducted a case - control study in small-scale, informal, hard-rock mining site in Northern Tanzania. We recruited all eligible active miners and ex-miners and matched non-miners aged $\geq 30$ years. We collected data on respiratory symptoms and risk factors using the BOLD questionnaire and performed spirometry with COPD defined based on post-bronchodilator FEV $1 / \mathrm{FVC}<70 \%$. We monitored air pollution based on PM 10 level in underground mining pits using TSI Side Pak TM AM510 samplers.

Results: A total of 851 men $₫ 577$ active miners, 211 ex-miners and 63 non-miners $₫$ were recruited with a mean age of $40.95 \pm 9.21$ years and two-thirds were cigarette smokers. About $83 \%$ of all respondents completed the questionnaires and underwent post-bronchodilator spirometry. The prevalence for COPD was estimated at $15.20 \%, 17.10 \%$ and $15.40 \%$ for active miners, ex-miners and non-miners respectively. Over $18 \%$ of current cigarette smokers had significant nicotine dependence which was associated with the duration of smoking $(p=0.028)$ and the number of pack years $(p=0.002)$. The majority of COPD patients presented with cough and had frequent exacerbations but with mild to moderate airway limitation. The majority of ex-miners presented with dyspnoea and had poor FEV 1 and FVC parameters. About $25 \%$ of COPD patients reported a history of pulmonary tuberculosis. The survey revealed up to $20000 \mu \mathrm{g} / \mathrm{m} 3$ of PM 10 in the underground drilling points; 400 -fold higher than the acceptable WHO limits.

Conclusion: There is high prevalence of COPD among small-scale miners in Tanzania. The patients are largely young and many are smoking cigarettes. The mining activities are typically carried out without protective gear. There is widespread lack of awareness of COPD and often people received inappropriate diagnosis and therapy.

\section{Background}

Chronic obstructive pulmonary disease (COPD) is an important cause of morbidity and mortality in developed countries, albeit with scarce data in Africa [1-3]. Cigarette smoking and occupational exposure to air pollution are well known risk factors for developing COPD worldwide [4, 5]. However, recently, exposure to biomass smoke and traffic pollution are increasingly recognized as major risk factors for developing COPD in developing countries [6]. In parallel, the current social and economic transitions in Africa characterized by increased urbanization, industrialization and extensive mineral explorations in the context of lack of work safety standards is likely to contribute to air pollution and increased exposure to occupational diseases. 
COPD is characterized by the presence of progressive and irreversible airway limitation resulting from chronic airway inflammatory response due to prolonged exposure to air pollutants [7]. COPD is a recent phenomenon in Africa as many patients with the disease are often misdiagnosed and managed as cases of adult-onset asthma using long-term inappropriate treatment options. The ageing populations together with increased cigarette smoking habits and the rising trends in air pollution are potential drivers for the continued rise in COPD in developing countries. Prolonged exposure to inhalational pollutants in specific occupational groups, who often don't use proper protective gear, exposes individuals to an increased risk of developing COPD.

Patients with COPD present with chronic cough and sputum production with or without dyspnoea. This clinical presentation tends to be ignored by patients until they present late at advanced stages of disease often after developing intolerable dyspnoea. Regrettably, due to lack of expertise and diagnostic facilities such as spirometry, patients with COPD are often misdiagnosed as cases of pulmonary tuberculosis or heart failure and offered inappropriate treatment [8]. The current management of COPD requires stepwise administration of bronchodilators and steroids preferably via the inhalational route during stable states and exacerbation. However, due to shortages of expertise and resources the guidelines based on the Global Initiative on Chronic Obstructive Lung Diseases (GOLD) are often not adhered to in routine clinical practice in Tanzania [8].

Currently, there are widespread, unregulated artisanal mining sites in Tanzania. The mining activities are characterized by lack of proper protective gear and weak regulatory authorities with a greater risk of exposure to excessive level of inhalational pollutants. In the current study we set to determine the burden of COPD in this high risk population and assess the air quality within the underground microenvironment where mining activities were undertaken.

\section{Methods}

Study area and study design: We conducted a cross-sectional study in a small-scale hard-rock mining site in Northern Tanzania. The mining site consists of large-scale and small-scale sites operated respectively by the large-scale investors and small-scale local miners. The small-scale mining site is organized into 100 mining pits across the site. Besides other minerals, tanzanite is a major mineral ore extracted from the area. The miners come from throughout Tanzania and nearby countries. In the current study we recruited three groups of participants namely; active miners, ex-miners and non-miners. The cases (active and ex-miners) were defined based on their exposure status. The latter served as controls recruited from the same, or nearby, areas. The study was preceded by conducting community sensitization meetings at the selected study sites.

Sampling and sample size estimation: We recruited 577 active miners and 211 ex-miners and 63 nonminers. We randomly selected 20 mining pits from the available 100 mining pits, from which we recruited a sample size of 577 active miners. The number of workers in each mining pit was pre-determined and all eligible participants were selected. A total of 211 ex-miners and 63 non-miners aged $\geq$ to 30 years were 
randomly selected and recruited from the local area. In the same study population, all households were visited and eligible ex-miners were identified for interview. From the same households we recruited eligible controls from individuals who had never been involved in the mining activities.

Fieldwork and data collection: We collected information about respiratory symptoms, occupation, respiratory diagnoses, co-morbidities, health care utilization, medication use, activity limitation, and health status together with basic demographic data and personal particulars. We also performed anthropometry measurements, and measured blood pressures and pulse. We assessed the burden and determinants of COPD using the BOLD protocol (www.boldstudy.org) with slight modification on demographic details and socioeconomic variables. The interviewers administered a set of BOLD validated questionnaires.

Participants underwent spirometry using 3L-syringe daily calibrated NDD EasyOne ${ }^{\mathrm{TM}}$ spirometer (www.nddmed.com) which was repeated 15 to 20 minutes after inhalation of $200 \mu \mathrm{g}$ of salbutamol via a spacer. The diagnosis of COPD was made based on a history of exposure to risk factors and the presence of airflow limitation that is not fully reversible, with or without the presence of symptoms. A postbronchodilator $\mathrm{FEV}_{1} / \mathrm{FVC}<70 \%$ and a post-bronchodilator (BD) $\mathrm{FEV}_{1}<80 \%$ predicted confirmed the presence of airflow limitation that is not fully reversible.

Pollution monitoring: Mining pits were monitored for air pollution in the underground microenvironments based on particulate matter with an aerodynamic diameter $<10 \mu \mathrm{m}\left(\mathrm{PM}_{10}\right)$ using TSI SidePak ${ }^{\mathrm{TM}}$ AM510 personal aerosol monitors (www.tsi.com) with a sampling rate of one minute. Two pre-programmed air sampler units were taken into the underground pits by the volunteer mining workers and positioned at two specific positions; the drilling point and at the rear of shaft where the rest of the miners hide during active drilling. The monitors were left at these positions for the up to 8 hours until the mining shift was over and then carried back to the fieldworkers.

\section{Results}

The current COPD survey recruited 851 male participants (577 active miners; 211 ex-miners and 63 nonminers). Over $53 \%$ of participants were in $31-40$ age-group and the mean age was $40.95 \pm 9.21$. Twothirds of all participants were either former or current cigarette smokers (Table 1). About $83 \%$ (702 of 851 ) of all respondents who completed the questionnaires underwent post-BD spirometry. Of these, $75 \%$ had received primary education and $73 \%$ had good nutritional status. About $68 \%, 25 \%$ and $7 \%$ of active miners, ex-miners and non-miners respectively reported either current or former cigarette smoking status (Table 2). Notably, over $40 \%$ of active miners were current smokers while about $48 \%$ of ex-miners were former cigarette smokers (Table 2).

The prevalence of COPD based on the criteria of post-BD $\mathrm{FEV}_{1} / \mathrm{FVC}<70 \%$, was estimated at $15.20 \%$, $17.10 \%$ and $15.40 \%$ for active miners, ex-miners and non-miners respectively (Table 3 ). However, the prevalence of COPD varied depending on the criteria used. Irrespective of the exposure category, the 
overall prevalence of COPD was $15.70 \%, 11.00 \%$ and $20.80 \%$ respectively based on post-BD $\mathrm{FEV}_{1} / \mathrm{FVC}$ $\leq 70 \%$, post BD FEV $1 / F V C<L L N$ and post-BD age category (Table 3 ). The prevalence of COPD generally increased with age in all exposure categories. Intriguingly, ex-miners had the highest prevalence (Table 4). Over $18 \%$ of all current cigarette smokers had significant nicotine dependence on the Fagerstrom scale (Table 5). This dependence was significantly associated with the duration of cigarette smoking $(p=$ $0.028)$ and the number of pack years $(p=0.002)$ (Table 6$)$.

Moreover, as highlighted in Table 7, it was noted that cough, followed by phlegm were the most common respiratory symptoms presented by patients with COPD irrespective of exposure categories. Moreover, shortness of breath was the least presenting symptom among all exposure categories which was reported by $46.4 \%$ of ex-miners and about $25 \%$ of both active miners and non-miners. The majority of COPD patients had increased frequency of 3 or more exacerbations within the preceding 12 months which was highest among active miners. The worst mean $\mathrm{FEV}_{1}$ andFVC parameters were noted among ex-miners and non-miners had the best mean spirometry parameters. Notwithstanding the exposure status, the majority of COPD patients had mild to moderate airway limitation which was reported in $84.9 \%, 79.2 \%$ and $87.5 \%$ respectively among active miners, ex-miners and non-miners. Noteworthy, the highest proportion of severe to very severe airway limitation was observed ex-miners and active miners.

The 8-hour measurements of air quality in underground mining microenvironments both at the rear of shaft and drilling points revealed levels of $\mathrm{PM}_{10}$ well beyond the acceptable $50 \mu \mathrm{g} / \mathrm{m}^{3}$ WHO limits (Fig. 1, 2 , and 3). The average exposure to $\mathrm{PM}_{10}$ was revealed to be nearly $5000 \mu \mathrm{g} / \mathrm{m}^{3}$ while the maximum exposure was beyond $20000 \mu \mathrm{g} / \mathrm{m}^{3}$ (Fig. 2 and 3 ).

\section{Discussion}

The prevalence of COPD ranged from 15 to $17 \%$ in the studied mining population in Tanzania in-line with previous studies conducted elsewhere $[9,10]$. These findings are comparable to population-based prevalence rates reported from recent COPD surveys in East Africa $[11,12]$. Intriguingly, the prevalence did not appear to differ significantly in relation to exposure status in our study. This observation could be explained by either the presence of confounding factors in the population or individuals who responded as non-miners might have worked intermittently in the mining activities and were thus misclassified as non-exposed [13]. Nearly all study populations irrespective of exposure status were exposed to biomass fuel and up to half of them were ever smokers indicating that other risk factors could contribute to the development of COPD in this study group.

The current study reported $40 \%$ and $48 \%$ of active and ex-miners respectively as current and former cigarette smokers. A study in Nigeria reported the prevalence of cigarette smoking in a community based study to range from $8.7 \%$ (current smokers) to $22 \%$ (in ever smokers) [14]. These figures suggest that the prevalence of cigarette smoking is typically much higher among miners compared to the general population. Notably, a substantial proportion of all current cigarette smokers had nicotine dependence on the Fagerstrom scale. These individuals are unlikely to quit smoking, thus constituting an at-risk 
population for developing COPD in the absence of purposeful therapeutic intervention for smoking cessation [15]. The interplay between cigarette smoking and occupational exposure to pollutants among miners accelerates the deterioration in lung function, particularly $\mathrm{FEV}_{1}$, and subsequent development of COPD $[16,17]$. This observation highlights the importance of integrating smoking cessation in the overall strategy for prevention of COPD $[18,19]$. Smoking cessation programs comprises the combination of psychotherapy together with pharmacotherapy, the latter constituting nicotine replacement therapy (NRT) together with specific drugs e.g. varenicline and bupropion slow release formulation $[19,20]$.

Besides cigarette smoking, ex-miners were more likely to be older than the active miners, thus age, as a determinant for cumulative risk exposure, could be contributing to the increased risk of developing COPD in susceptible individuals [21]. Further explanation would be the fact that in an unregulated mining industry, people tend to retire from the mining activities when they develop intolerable dyspnoea. It is thus prudent to suspect that some ex-miners retired from working after developing COPD, thus, contributing to a higher burden of disease in among the ex-miners compared to the active miners.

Similar to other studies conducted elsewhere, patients with COPD commonly presented with cough as a predictor of progression while breathlessness or dyspnoea signifies severity [22]. In the current study, it was revealed that the majority of ex-miners with COPD presented with dyspnoea which could indicate disease severity probably also associated with inadequate treatment. This observation is in line with other previous studies which reported dyspnoea as a predictor of disease severity [23, 24]. The majority of COPD patients had increased frequency of exacerbations regardless of their exposure status which could indicate inadequate or inappropriate disease management. It was further observed that ex-miners had the worst mean spirometry parameters including $\mathrm{FEV}_{1}, \mathrm{FVC}$ and $\mathrm{FEV}_{1} / \mathrm{FVC}$, However, these poor spirometry results were not reflected in the clinical manifestation and disease severity. Notwithstanding the exposure status, the majority of COPD patients had mild to moderate airway limitation as assessed by GOLD classification. It remains elusive whether the small proportion of patients with severe COPD might be explained by increased mortality in this study group.

Accurate diagnosis and proper administration of appropriate drugs through appropriate routes and duration are keys to the reduction of patients' suffering and mortality. The shortage of expertise in respiratory medicine and lack of diagnostic facilities including spirometry are major hurdles in the management of patients with COPD in Africa [1]. In the absence of proper diagnosis, patients with COPD may be misdiagnosed for other conditions including pulmonary tuberculosis. For instance, in our study $10 \%$ of patients were reported to have a history of pulmonary tuberculosis (TB). However, it is well known that miners constitute a population group at increased risk for developing pulmonary TB thus highlighting the possibility of co-morbidity [25-27]. In particular, several studies indicate the presence of latent TB among hard-rock miners in the absence of predetermined exposure [27]. Standard guidelines for management of COPD are often not adhered to resulting in increased adverse effects and poor healthrelated quality of life. The current study revealed the inappropriate use of drugs, which are often administered through inappropriate routes and intermittently rather than regularly [28]. For instance, aminophyline was the most commonly prescribed medication for respiratory symptoms in all 
respondents including patients with COPD. The current, 2017 GOLD guidelines recommend limited use of methylxanthines due to their limited clinical efficacy and narrow therapeutic index [29].

The 24-hour measurements of air quality in underground mining tunnels and blasting sections revealed extremely high levels of $\mathrm{PM}_{10}$ well beyond the WHO acceptable safety limits [30]. As depicted in Figure 2 and 3 , the survey revealed up to $5000 \mu \mathrm{g} / \mathrm{m}^{3}$ of $\mathrm{PM}_{10} ; 100$-fold higher than the acceptable WHO limits of $50 \mu \mathrm{g} / \mathrm{m}^{3}$. The miners, who are invariably without protective gear, are constantly exposed to these extreme levels of air pollution. The existing weak health regulatory authorities without monitoring of mining safety practices expose miners to increased risk of dust exposure and consequent risk of chronic respiratory diseases including COPD.

\section{Conclusions}

The current study reported a substantial burden of COPD among young miners in Tanzania. Our study affirms that cigarette smoking and air pollution are important risk factors for developing COPD.

Furthermore, the study revealed that the small-scale mining companies in the study area do not have appropriate technology and facilities to ensure protection of workers. Intriguingly, patients identified with COPD are not aware of their diagnoses and the majority are frequently misdiagnosed and mismanaged. The best practice protocol by GOLD guidelines for management of patients with COPD is not routinely observed. This inadequate treatment often results in frequent exacerbations, hospitalizations and poor health-related quality of life.

These research findings suggest the need for the urgent development of a national social protection and legal framework for occupational health in Tanzania. The strategies may include development of better approaches for enforcement of policy and regulations for promotion of workers' health and prevention of occupational diseases; and empowerment of health facilities with skills and capacity for improving practice and uptake of existing management guidelines for COPD in Tanzania.

\section{Abbreviations}

$\mathrm{BD}$

Bronchodilator

BOLD

Burden of Obstructive Lung Diseases

COPD

Chronic Obstructive Pulmonary Disease

FEV1 
Forced Expiratory Volume, at 1 second

FVC

Forced Vital Capacity

GOLD

Global Obstructive Lung Disease

GSK

GlaxoSmithKline

IHI

Ifakara Health Institute

NDD

New Diagnostic Design

NRT

Nicotine Replacement Therapy

PM10

Particulate Matter, $10 \mu \mathrm{m}$ in diameter

TB

Pulmonary Tuberculosis

WHO

World Health Organization

\section{Declarations}

\section{Ethics approval and Consent to participate}

This study was approved by the National Institute for Medical Research (NIMR) Ethics Committee in Tanzania and conducted in accordance with Helsinki Declaration on the study on human subjects. All participants consented to participate in the study. 


\section{Consent to publish}

All participants were requested for and consented for the permission to publish the study findings.

\section{Availability of data and materials}

All raw data pertaining to this study are stored at an institutional repository with secure back up. Both raw and processed data can be retrieved and made available to the third party upon request according to the institutional regulations.

\section{Competing interests}

All authors declare no competing interests.

\section{Funding}

This study was conducted by Ifakara Health Institute $(\mathrm{IHI})$ in collaboration with other investigators through financial support from GlaxoSmithKline (GSK) Ltd through Trust in Science-Africa initiative.

\section{Authors' contributions}

NFM and RWW conceived and designed the study. The study was reviewed by MDS, JDM, AKN and SSS. NFM, MDS, JDM, AKN and AAS developed training materials and offered training to the fieldworkers. ASS coordinated and supervised the field activities, performed spirometry and supervised data entry. SSS, KKA and SJM performed statistical analysis. NFM prepared the results and wrote the first draft of the manuscript. All investigators reviewed the final version of the manuscript.

\section{Acknowledgements}

We are grateful to BOLD UK (www.boldstudy.org) for the permission to use their study protocol. We thank administrative and health authorities in Simanjiro and Hai districts for the permission to conduct this study. We are also grateful for the support from all fieldworkers and all COPD project administrative staff at IHI. We are greatly indebted to all study participants.

\section{References}

1.Mehrotra, A., A.M. Oluwole, and S. B. Gordon, The burden of COPD in Africa: a literature review and prospective survey of the availability of spirometry for COPD diagnosis in Africa. Trop Med Int Health, 2009. 14(8): p. 840-8. 
2.Groenewald, P., et al., Estimating the burden of disease attributable to smoking in South Africa in 2000. S Afr Med J, 2007. 97(8 Pt 2): p. 674-81.

3.Chan-Yeung, M., et al., The burden and impact of COPD in Asia and Africa. Int J Tuberc Lung Dis, 2004. $8(1)$ : p. 2-14.

4.Boschetto, P., et al., Chronic obstructive pulmonary disease (COPD) and occupational exposures. J Occup Med Toxicol, 2006. 1: p. 11.

5.Becklake, M. R., Occupational exposures: evidence for a causal association with chronic obstructive pulmonary disease. Am Rev Respir Dis, 1989. 140(3 Pt 2): p. S85-91.

6.Salvi, S., The silent epidemic of COPD in Africa. Lancet Glob Health. 3(1): p. e6-7.

7.Musil, J., [Pathogenesis of the chronic obstructive pulmonary disease (COPD)]. Vnitr Lek, 2004. 50(9): p. 663-7.

8.Chan-Yeung, M., et al., Management of chronic obstructive pulmonary disease in Asia and Africa. Int $\mathrm{J}$ Tuberc Lung Dis, 2004. 8(2): p. 159-70.

9.Balmes, J., et al., American Thoracic Society Statement: Occupational contribution to the burden of airway disease. Am J Respir Crit Care Med, 2003. 167(5): p. 787-97.

10.Fishwick, D., et al., Occupational chronic obstructive pulmonary disease: a standard of care. Occup Med (Lond). 65(4): p. 270-82.

11.Magitta, N. F., et al., Prevalence, risk factors and clinical correlates of COPD in a rural setting in Tanzania. Eur Respir J. 51(2).

12.van Gemert, F., et al., Prevalence of chronic obstructive pulmonary disease and associated risk factors in Uganda (FRESH AIR Uganda): a prospective cross-sectional observational study. Lancet Glob Health. 3(1): p. e44-51.

13.David B. Richardson, D. L., Mary K. Schubauer-Berigan, Eric Tchetgen Tchetgen, and Stephen R. Cole, Assessment and Indirect Adjustment for Confounding by Smoking in Cohort Studies Using Relative Hazards Models. Am J Epidemiol., 2014. 180(9): p. 933-940.

14.Adeloye, D., et al., An estimate of the prevalence of COPD in Africa: a systematic analysis. COPD. 12(1): p. 71-81.

15.Laniado-Laborin, R., Smoking and chronic obstructive pulmonary disease (COPD). Parallel epidemics of the 21 century. Int J Environ Res Public Health, 2009. 6(1): p. 209-24.

16.Santo Tomas, L. H., Emphysema and chronic obstructive pulmonary disease in coal miners. Curr Opin Pulm Med. 17(2): p. 123-5. 
17.Vinnikov, D., Drillers and mill operators in an open-pit gold mine are at risk for impaired lung function. J Occup Med Toxicol. 11: p. 27.

18.Li, Y., et al., Smoking cessation and COPD mortality among Japanese men and women: the JACC study. Prev Med. 55(6): p. 639-43.

19.Tonnesen, P., Smoking cessation and COPD. Eur Respir Rev. 22(127): p. 37-43.

20.Strassmann, R., et al., Smoking cessation interventions in COPD: a network meta-analysis of randomised trials. Eur Respir J, 2009. 34(3): p. 634-40.

21.Geijer, R. M., et al., Incidence and determinants of moderate COPD (GOLD II) in male smokers aged 4065 years: 5-year follow up. Br J Gen Pract, 2006. 56(530): p. 656-61.

22.Smith, J. and A. Woodcock, Cough and its importance in COPD. Int J Chron Obstruct Pulmon Dis, 2006. 1(3): p. 305-14.

23.Nishimura, K., et al., Dyspnea is a better predictor of 5-year survival than airway obstruction in patients with COPD. Chest, 2002. 121(5): p. 1434-40.

24.O'Donnell, D. E., et al., Exertional dyspnoea in COPD: the clinical utility of cardiopulmonary exercise testing. Eur Respir Rev. 25(141): p. 333-47.

25.Isidro Montes, I., et al., Respiratory disease in a cohort of 2,579 coal miners followed up over a 20-year period. Chest, 2004. 126(2): p. 622-9.

26.Girdler-Brown, B. V., et al., The burden of silicosis, pulmonary tuberculosis and COPD among former Basotho goldminers. Am J Ind Med, 2008. 51(9): p. 640-7.

27.Ringshausen, F. C., et al., Frequent detection of latent tuberculosis infection among aged underground hard coal miners in the absence of recent tuberculosis exposure. PLoS One. 8(12): p. e82005.

28.Bateman, E. D., et al., Guideline for the management of chronic obstructive pulmonary disease (COPD): 2004 revision. S Afr Med J, 2004. 94(7 Pt 2): p. 559-75.

29.GOLD, Global Initiative for Chronic Obstructive Lung Disease: Global strategy for the diagnosis, management, and prevention of COPD. 2017.

30.WHO, WHO Air quality guidelines for particulate matter, ozone, nitrogen dioxide and sulfur dioxide. 2005.

\section{Tables}


Table 1: Demographic characteristics of responders who completed survey questionnaire

\begin{tabular}{|c|c|c|c|}
\hline \multirow[t]{2}{*}{ Study variable } & \multicolumn{3}{|c|}{ Responders $(\mathrm{N}=851)$} \\
\hline & & Number & Percentage \\
\hline Gender & Male & 851 & $100.00 \%$ \\
\hline \multirow[t]{5}{*}{ Age-group in years } & $20-30$ & 20 & $2.40 \%$ \\
\hline & $31-40$ & 453 & $53.20 \%$ \\
\hline & $41-50$ & 249 & $29.30 \%$ \\
\hline & $51-60$ & 90 & $10.60 \%$ \\
\hline & $60+$ & 39 & $4.60 \%$ \\
\hline Mean age (in years) & \multicolumn{3}{|c|}{$40.95 \pm 9.21$} \\
\hline \multirow[t]{2}{*}{ Smoking status } & Never smokers & 288 & $33.80 \%$ \\
\hline & Smokers & 563 & $66.20 \%$ \\
\hline \multirow[t]{3}{*}{ Exposure status } & Non-miners & 63 & $7.40 \%$ \\
\hline & Ex-miners & 211 & $24.79 \%$ \\
\hline & Active miners & 577 & $67.80 \%$ \\
\hline
\end{tabular}

Table 2: Demographic characteristics of responders who completed questionnaire and postbronchodilator spirometry $(\mathrm{N}=702)$

\begin{tabular}{lccccc}
\hline Variable & & \multicolumn{2}{c}{ Exposure status } & \\
& & Active miners & Ex miners & Non-miners & Total \\
\hline Gender & Male & $480(68.40 \%)$ & $170(24.20 \%)$ & $52(7.40 \%)$ & $702(100.00 \%)$ \\
\hline Education & & & & \\
\hline & Primary Education & $358(74.70 \%)$ & $137(80.60 \%)$ & $33(63.50 \%)$ & $528(75.30 \%)$ \\
\hline & Secondary Education & $53(11.10 \%)$ & $17(10.00 \%)$ & $8(15.40 \%)$ & $78(11.10 \%)$ \\
\hline & Others & $14(2.92 \%)$ & $2(1.18 \%)$ & $6(11.54 \%)$ & $22(3.14 \%)$ \\
\hline & No education & $52(10.90 \%)$ & $14(8.20 \%)$ & $5(9.60 \%)$ & $71(10.10 \%)$ \\
\hline Body mass index & Unknown & $2(0.40 \%)$ & $0(0.00 \%)$ & $0(0.00 \%)$ & $2(0.30 \%)$ \\
\hline & & & & & $45(6.50 \%)$ \\
\hline & Underweight & $27(5.70 \%)$ & $13(7.70 \%)$ & $5(9.60 \%)$ & $407(72.80 \%)$ \\
\hline & Normal weight & $369(77.70 \%)$ & $112(66.30 \%)$ & $26(50.00 \%)$ & $507(17.00 \%)$ \\
\hline Smoking status & Overweight & $65(13.70 \%)$ & $37(21.90 \%)$ & $16(30.80)$ & $118(17.00 \%)$ \\
\hline & Obesity & $14(2.90 \%)$ & $7(4.10 \%)$ & $5(9.60 \%)$ & $26(3.70 \%)$ \\
\hline & & & & & \\
\hline & Non-smokers & $163(34.00 \%)$ & $45(26.50 \%)$ & $28(53.80 \%)$ & $236(33.60 \%)$ \\
\hline
\end{tabular}

Table 3: Prevalence rates of COPD among active miners, ex-miners and non-miners based on different diagnostic criteria 


\begin{tabular}{lccccc}
\hline \multicolumn{1}{c}{ Variable } & COPD status & \multicolumn{4}{c}{ Miner's status } \\
& & Active miners & Ex miners & Non-miners & Total \\
\hline COPD ${ }^{1}$ Post Test Result & Yes & $73(15.20 \%)$ & $29(17.10 \%)$ & $8(15.40 \%)$ & $110(15.70 \%)$ \\
& No & 407 & 141 & 44 & 592 \\
\hline & \multicolumn{7}{c}{5} & & & \\
\hline COPD $^{2}$ LLN PB Post Test Result & Yes & $56(11.70 \%)$ & $17(10.00 \%)$ & $4(7.70 \%)$ & $77(11.00 \%)$ \\
\hline & No & 424 & 153 & 48 & 625 \\
\hline COPD $^{3}$ Age Post Test Result & Yes & $104(21.70 \%)$ & $35(20.60 \%)$ & $7(13.50 \%)$ & $146(20.80 \%)$ \\
\hline & No & 376 & 135 & 45 & 556 \\
\hline
\end{tabular}

1: Post-BD FEV1/FVC<70\%; 2: Post-BD FEV1/FVC<LLN; and 3: Age <40 years; Post-BD FEV1/FVC <75\%; Age (40-60) years; Post-BD FEV1/FVC $<70 \%$ and Age $<60$ years Post-BD FEV1/FVC $<65 \%$.

Table 4: Prevalence rates of COPD by exposure group and age-categories among respondents

\begin{tabular}{|c|c|c|c|c|c|c|c|}
\hline \multirow[t]{2}{*}{ Exposure categories } & \multirow[t]{2}{*}{ COPD } & \multicolumn{6}{|c|}{ Age-categories } \\
\hline & & 30.01 to 40 & 40.01 to 40 & 40.01 to 50 & 50.01 to 60 & Above 60 & Total \\
\hline \multirow[t]{4}{*}{ Active miners } & Yes & 0 & 26 & 30 & 9 & 8 & 73 \\
\hline & & $0.00 \%$ & $8.70 \%$ & $22.70 \%$ & $32.10 \%$ & $66.70 \%$ & $15.20 \%$ \\
\hline & No & 9 & 272 & 102 & 19 & 4 & 406 \\
\hline & & $100.0 \%$ & $91.30 \%$ & $77.30 \%$ & $67.90 \%$ & $33.30 \%$ & $84.80 \%$ \\
\hline \multirow[t]{4}{*}{ Ex-miners } & Yes & 0 & 3 & 12 & 8 & 5 & 28 \\
\hline & & $0.00 \%$ & $5.30 \%$ & $21.40 \%$ & $21.60 \%$ & $33.30 \%$ & $16.60 \%$ \\
\hline & No & 4 & 54 & 44 & 29 & 10 & 141 \\
\hline & & $100.0 \%$ & $94.70 \%$ & $78.60 \%$ & $78.40 \%$ & $66.70 \%$ & $83.40 \%$ \\
\hline \multirow[t]{4}{*}{ Non-miners } & Yes & 0 & 0 & 3 & 2 & 3 & 8 \\
\hline & & $0.00 \%$ & $0.00 \%$ & $20.00 \%$ & $15.40 \%$ & $42.90 \%$ & $15.40 \%$ \\
\hline & No & 5 & 12 & 12 & 11 & 4 & 44 \\
\hline & & $100.0 \%$ & $100.0 \%$ & $80.0 \%$ & $84.60 \%$ & $57.10 \%$ & $84.60 \%$ \\
\hline
\end{tabular}

1 Post-BD FEV1/FVC $<70 \%$

Table 5: Distribution of Fagarstrom nicotine score scale and nicotine dependence among ever cigarette smokers by mining exposure categories 


\begin{tabular}{|c|c|c|c|c|c|}
\hline Variable & & \multicolumn{4}{|c|}{ Miner's status } \\
\hline & & Active & Ex & Non- & Total \\
\hline & & Miner & Miner & Miner & \\
\hline \multirow{19}{*}{$\begin{array}{l}\text { Fagarstrom Nicotine score } \\
\text { scale }\end{array}$} & 0 & 27 & 4 & 0 & 31 \\
\hline & & $17.31 \%$ & $14.81 \%$ & $0.00 \%$ & $16.67 \%$ \\
\hline & 1 & 30 & 5 & 1 & 36 \\
\hline & & $19.23 \%$ & $18.52 \%$ & $33.33 \%$ & $19.35 \%$ \\
\hline & 2 & 25 & 2 & 0 & 27 \\
\hline & & $16.03 \%$ & $7.41 \%$ & $0.00 \%$ & $14.52 \%$ \\
\hline & 3 & 24 & 4 & 0 & 28 \\
\hline & & $15.38 \%$ & $14.81 \%$ & $0.00 \%$ & $15.05 \%$ \\
\hline & 4 & 24 & 6 & 0 & 30 \\
\hline & & $15.38 \%$ & $22.22 \%$ & $0.00 \%$ & $16.13 \%$ \\
\hline & 5 & 12 & 4 & 1 & 17 \\
\hline & & $7.69 \%$ & $14.81 \%$ & $33.33 \%$ & $9.14 \%$ \\
\hline & 6 & 8 & 0 & 1 & 9 \\
\hline & & $5.13 \%$ & $0.00 \%$ & $33.33 \%$ & $4.84 \%$ \\
\hline & 7 & 2 & 1 & 0 & 3 \\
\hline & & $1.28 \%$ & $3.70 \%$ & $0.00 \%$ & $1.61 \%$ \\
\hline & 8 & 4 & 1 & 0 & 5 \\
\hline & & $2.56 \%$ & $3.70 \%$ & $0.00 \%$ & $2.69 \%$ \\
\hline & Total & 156 & 27 & 3 & 186 \\
\hline \multirow[t]{5}{*}{ Nicotine dependency scale } & $\begin{array}{l}\text { Low to moderate } \\
\text { dependency } \\
\text { (score } 0 \text { to } 4 \text { ) }\end{array}$ & 130 & 21 & 1 & 152 \\
\hline & & $83.33 \%$ & $77.78 \%$ & $33.33 \%$ & $81.72 \%$ \\
\hline & $\begin{array}{l}\text { Significant dependency } \\
\text { (score }>=5 \text { ) }\end{array}$ & 26 & 6 & 2 & 34 \\
\hline & & $16.67 \%$ & $22.22 \%$ & $66.67 \%$ & $18.28 \%$ \\
\hline & Total & 156 & 27 & 3 & 186 \\
\hline
\end{tabular}

Table 6: Association between nicotine dependence and selected variables among current cigarette smokers 


\begin{tabular}{|c|c|c|c|c|c|c|c|c|}
\hline Variable & $\begin{array}{l}\text { Nicotine Addiction } \\
\text { Scale }\end{array}$ & $\mathbf{N}$ & Mean & SD & $\begin{array}{c}\text { Mean } \\
\text { difference }\end{array}$ & $\begin{array}{l}95 \% \\
\text { Lower CI }\end{array}$ & $\begin{array}{c}95 \% \\
\text { Upper } \\
\text { CI }\end{array}$ & $\begin{array}{c}\mathrm{p}- \\
\text { Value }\end{array}$ \\
\hline \multirow[t]{2}{*}{ Age } & $\begin{array}{l}\text { Low to Moderate } \\
\text { Dependence }\end{array}$ & 152 & 39.96 & 8.21 & \multirow[t]{2}{*}{-2.929} & \multirow[t]{2}{*}{-6.109} & \multirow[t]{2}{*}{0.251} & \multirow[t]{2}{*}{0.071} \\
\hline & $\begin{array}{l}\text { Significant } \\
\text { Dependence }\end{array}$ & 34 & 42.89 & 9.71 & & & & \\
\hline \multirow[t]{2}{*}{$\begin{array}{l}\text { Number of } \\
\text { smoking years }\end{array}$} & $\begin{array}{l}\text { Low to Moderate } \\
\text { Dependence }\end{array}$ & 152 & 19.28 & 9.58 & \multirow[t]{2}{*}{-4.113} & \multirow[t]{2}{*}{-7.778} & \multirow[t]{2}{*}{-0.449} & \multirow[t]{2}{*}{0.028} \\
\hline & $\begin{array}{l}\text { Significant } \\
\text { Dependence }\end{array}$ & 34 & 23.39 & 10.72 & & & & \\
\hline \multirow[t]{2}{*}{$\begin{array}{l}\text { Number of pack } \\
\text { years }\end{array}$} & $\begin{array}{l}\text { Low to Moderate } \\
\text { Dependence }\end{array}$ & 152 & 8.33 & 7.86 & \multirow[t]{2}{*}{-30.742} & \multirow[t]{2}{*}{-72.536} & \multirow[t]{2}{*}{11.052} & \multirow[t]{2}{*}{0.002} \\
\hline & $\begin{array}{l}\text { Significant } \\
\text { Dependence }\end{array}$ & 34 & 39.08 & 119.73 & & & & \\
\hline
\end{tabular}

Table 7: Respiratory symptoms, exercitations, spirometry indices and COPD severity based on GOLD classification among total study population

\begin{tabular}{|c|c|c|c|}
\hline \multirow[t]{2}{*}{ Clinical characteristics } & \multicolumn{3}{|c|}{ Exposure categories } \\
\hline & Active miners $(\mathrm{n}=73)$ & Ex-miners $(n=28)$ & Non-miners $(n=8)$ \\
\hline \multicolumn{4}{|l|}{ Respiratory symptoms } \\
\hline Cough & $38(52.1 \%)$ & $18(64.2 \%)$ & $7(87.5 \%)$ \\
\hline Phlegm & $34(46.6 \%)$ & $15(53.6 \%)$ & $5(62.5 \%)$ \\
\hline Wheeze & $29(39.7 \%)$ & $15(53.6 \%)$ & $3(37.5 \%)$ \\
\hline Shortness of breath & $17(25.8 \%)$ & $13(46.4 \%)$ & $2(25.0 \%)$ \\
\hline \multicolumn{4}{|c|}{ Exacerbation in the past 12 months } \\
\hline 0 & $3(12.0 \%)$ & $3(23.1 \%)$ & $0(0.0 \%)$ \\
\hline 1 & $4(16.0 \%)$ & $1(7.7 \%)$ & $1(33.3 \%)$ \\
\hline 2 & $4(16.0 \%)$ & $5(38.5 \%)$ & $1(33.3 \%)$ \\
\hline 3 or more & $14(56.0 \%)$ & $4(30.7 \%)$ & $1(33.3 \%)$ \\
\hline \multicolumn{4}{|l|}{ Post-Test spirometry } \\
\hline FVC (\% predicted) & $92.90 \pm 19.79$ & $88.73 \pm 25.14$ & $104.72 \pm 23.07$ \\
\hline FEV1 (\% predicted) & $70.18 \pm 18.31$ & $62.98 \pm 17.09$ & $78.68 \pm 18.85$ \\
\hline \multicolumn{4}{|c|}{ Severity of airway limitation in GOLD classification } \\
\hline 1 (Mild obstruction) & $22(30.1 \%)$ & $6(20.7 \%)$ & $4(50.0 \%)$ \\
\hline 2 (Moderate obstruction) & $40(54.8 \%)$ & $17(58.6 \%)$ & $3(37.5 \%)$ \\
\hline 3 (Severe obstruction) & $10(13.7 \%)$ & $4(13.8 \%)$ & $1(12.5 \%)$ \\
\hline 4 (Very severe obstruction) & $1(1.4 \%)$ & $2(6.9 \%)$ & $0(0.0 \%)$ \\
\hline
\end{tabular}




\section{Figures}

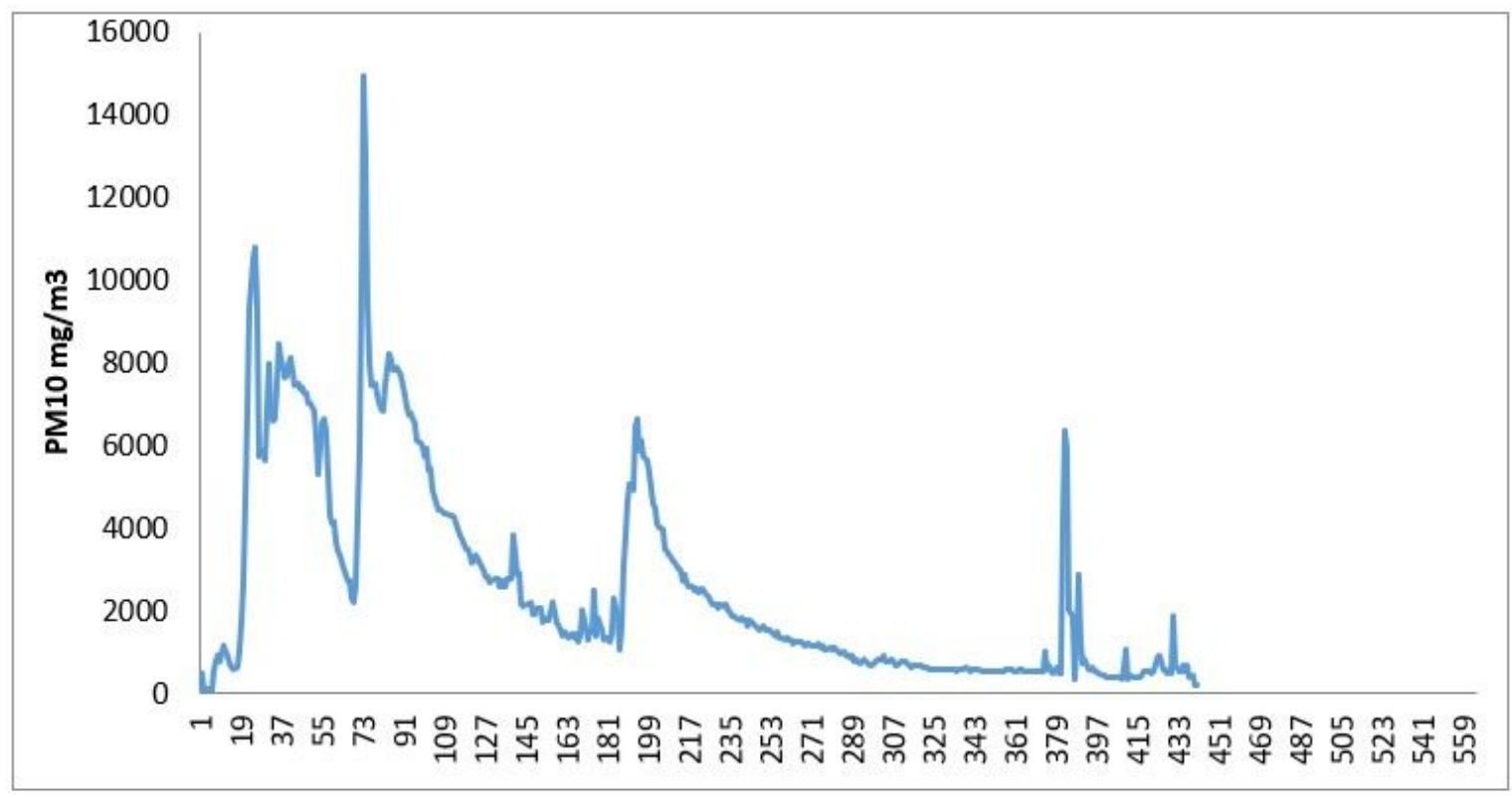

Figure 1: Graphical variation of $\mathrm{PM}_{10}$ in a typical 8-hour monitoring session in underground mining pit in a hard-rock mining site, Northern Tanzania

\section{Figure 1}

Graphical variation of PM10 in a typical 8-hour monitoring session in underground mining pit in a hardrock mining site, Northern Tanzania 


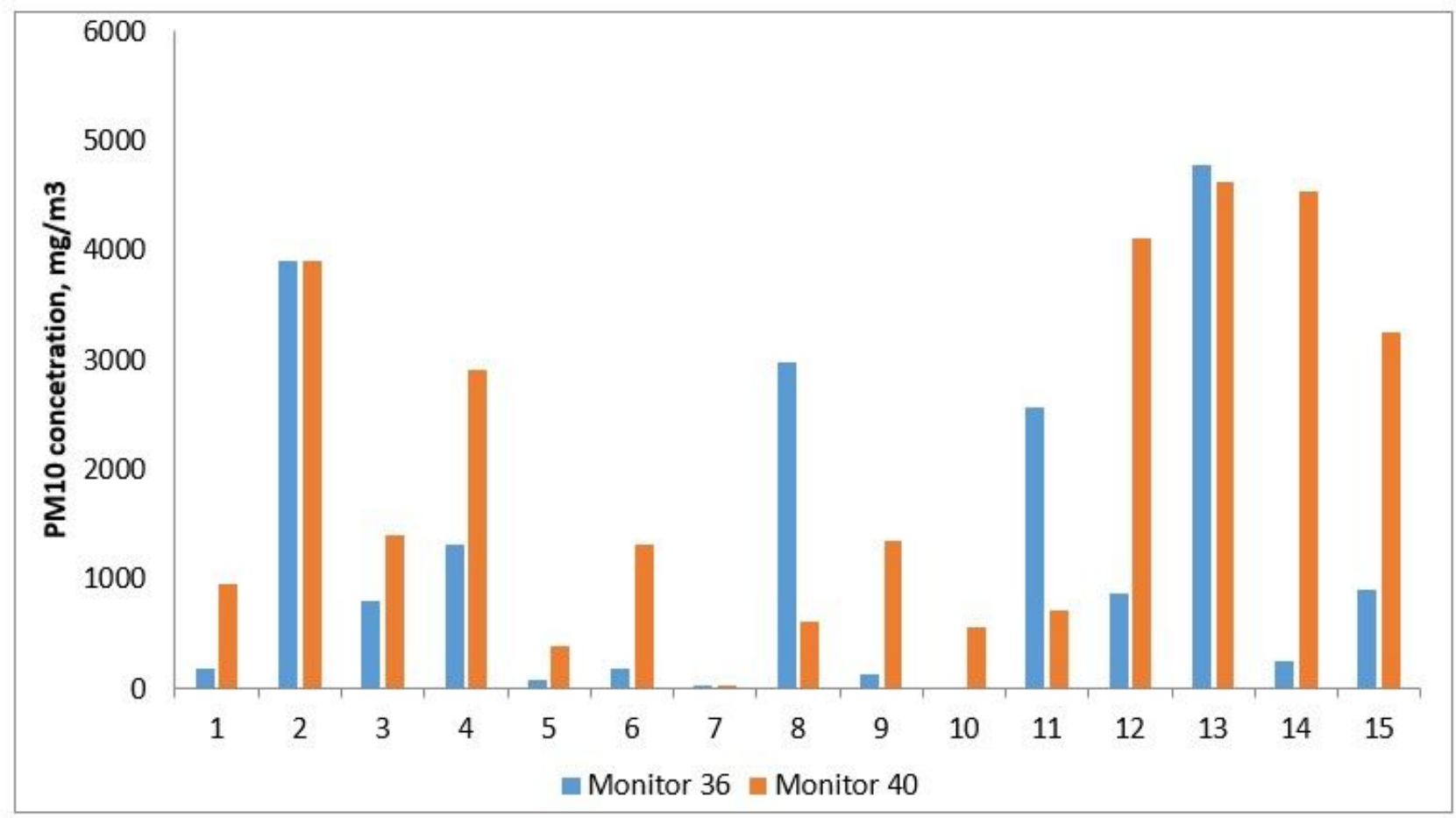

Figure 2

Variation in daily average PM10 concentrations for two monitors situated at the drilling point (monitor serial 40) and rear of shaft (monitor serial 36) in a typical underground microenvironment in 15 selected hard-rock mining pits, Northern Tanzania..

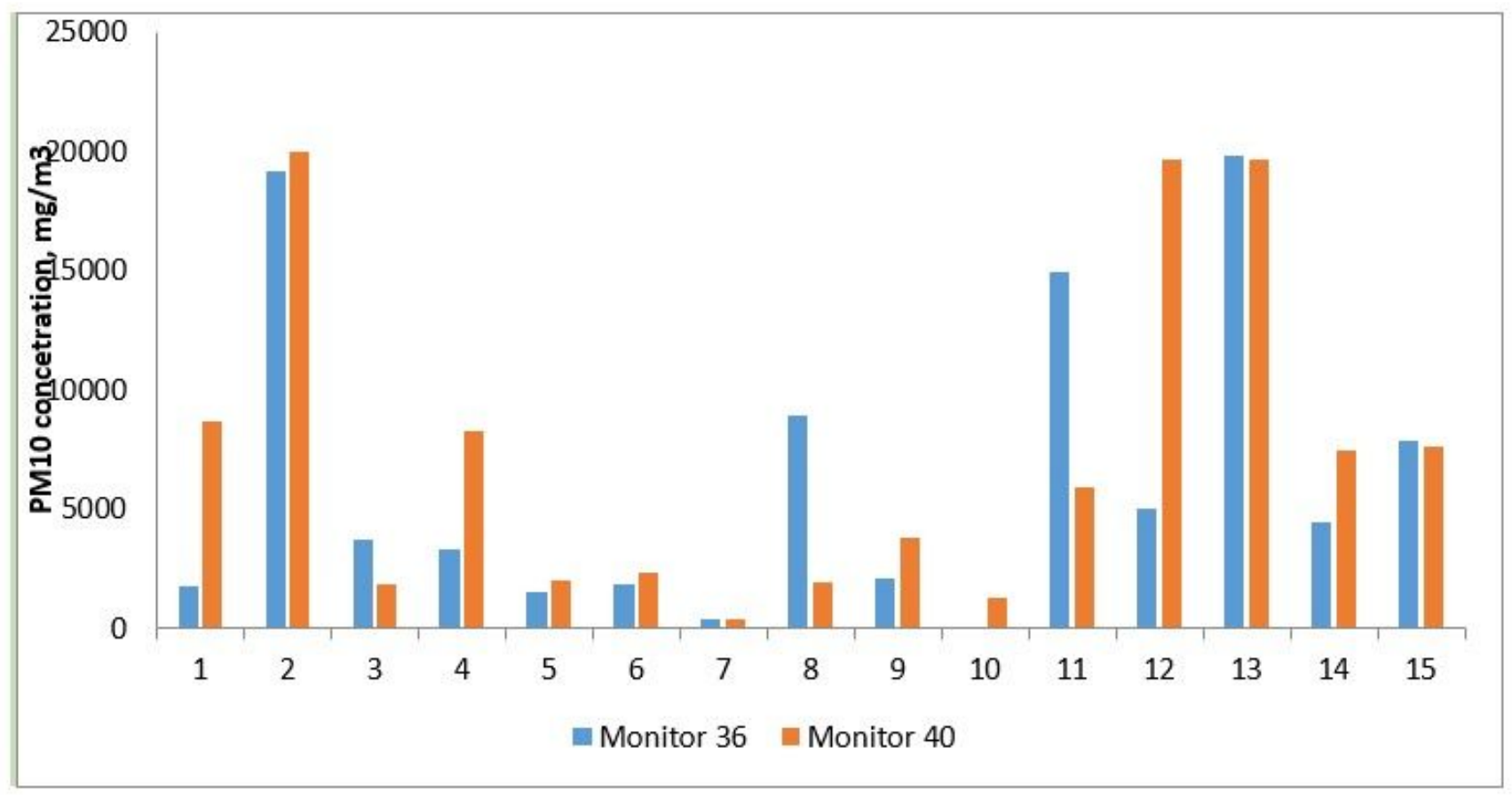




\section{Figure 3}

Variation in daily maximum values of PM10 concentrations for two monitors situated at the drilling point (monitor serial 40) and rear of shaft (monitor serial 36) in a typical underground microenvironment in 15 selected hard-rock mining pits, Northern Tanzania. 